\title{
Cross-Language Multimedia Information Retrieval
}

\author{
Sharon Flank \\ eMotion, Inc. \\ 2600 Park Tower Dr., Vienna, VA 22180 USA \\ sharon.flank@emotion.com
}

\section{Abstract}

Simple measures can achieve high-accuracy cross-language retrieval in carefully chosen applications. Image retrieval is one of those applications, with results ranging from $68 \%$ of human translator performance for German, to $100 \%$ for French.

\section{Introduction}

Information is increasingly global, and the need to access it crosses language barriers. The topic of this paper, cross-language information retrieval, concerns the automatic retrieval of text in one language via a query in a different language. A considerable body of literature has grown up around cross-language information retrieval (e.g. Grefenstette 1998, TREC-7 1999). There are two basic approaches. Either the query can be translated, or each entire document can be translated into the same language as the query. The accuracy of retrieval across languages, however, is generally not good. One of the weaknesses that plagues crosslanguage retrieval is that we do not have a good sense of who the users are, or how best to interact with them.

In this paper we describe a multimedia application for which cross-language information retrieval works particularly well. eMotion, Inc. has developed a natural language information retrieval application that retrieves images, such as photographs, based on short textual descriptions or captions. The captions are typically one to three sentences, although they may also contain strings of keywords. Typical queries are, as in most Web search applications, two to three words in length. At this point, all of the captions are in English. eMotion hosts a large database of images for sale and for licensing, PictureQuest. At least $10 \%$ of PictureQuest's user base is outside the United States. The tests were performed on the PictureQuest database of approximately 400,000 images.

Recent Web utilization data for PictureQuest indicate that of the $10 \%$ of users from outside the United States, a significant portion come from Spanish-speaking, French-speaking, and German-speaking countries. It is expected that adding appropriate language interfaces and listing PictureQuest in foreign-language search engines will dramatically increase nonEnglish usage.

\section{The Cross-Language Multimedia Retrieval Application}

This paper offers several original contributions to the literature on crosslanguage information retrieval. First, the choice of application is novel, and significant because it simplifies the language problem enough to make it tractable. Because the objects retrieved are images and not text, they are instantly comprehensible to the user regardless of language issues. This fact makes it possible for users to perform a relevance assessment without the need for any kind of translation. More important, users themselves can select objects of interest, without recourse to translation. The images are, in fact, 
associated with caption information, but, even in the monolingual system, few users ever even view the captions. It should be noted that most of the images in PictureQuest are utilized for advertising and publishing, rather than for news applications. Users of history and news photos do tend to check the captions, and often users in publishing will view the captions. For advertising, however, what the image itself conveys is far more important than the circumstances under which it was created.

Another significant contribution of this paper is the inclusion of a variety of machine translation systems. None of the systems tested is a high-end machine translation system: all are freely available on the Web.

Another key feature of this paper is the careful selection of an accuracy measure appropriate to the circumstances of the application. The standard measure, percent of monolingual performance achieved, is used, with a firm focus on precision. In this application, users are able to evaluate only what they see, and generally have no idea what else is present in the collection. As a result, precision is of far more interest to customers than recall. Recall is, however, of interest to image suppliers, and in any case it would not be prudent to optimize for precision without taking into account the recall tradeoff.

The PictureQuest application avoids several of the major stumbling blocks that stand in the way of high-accuracy cross-language retrieval. Ballesteros and Croft (1997) note several pitfalls common to cross-language information retrieval:
(1) The dictionary may not contain specialized vocabulary (particularly bilingual dictionaries).

(2) Dictionary translations are inherently ambiguous and add extraneous terms to the query.

(3) Failure to translate multi-term concepts as phrases reduces effectiveness.

In the PictureQuest application, these pitfalls are minimized because the queries are short, not paragraph-long descriptions as in TREC (see, e.g., Voorhees and Harman 1999). This would be a problem for a statistical approach, since the queries present little context, but, since we are not relying on context (because reducing ambiguity is not our top priority) it makes our task simpler. Assuming that the translation program keeps multi-term concepts intact, or at least that it preserves the modifier-head structure, we can successfully match phrases. The captions (i.e. the documents to be retrieved) are mostly in sentences, and their phrases are intact. The phrase recognizer identifies meaningful phrases (e.g. fire engine) and handles them as a unit. The pattern matcher recognizes core noun phrases and makes it more likely that they will match correctly.

Word choice can be a major issue as well for cross-language retrieval systems. Some ambiguity problems can be resolved through the use of a part-of-speech tagger on the captions. As Resnik and Yarowsky (in press) observe, part-of-speech tagging considerably reduces the word sense disambiguation problem. However, some ambiguity remains. For example, the decision to translate a word as car, automobile, or vehicle, may dramatically affect retrieval accuracy. The PictureQuest 
system uses a semantic net based on WordNet (Fellbaum 1998) to expand terms. Thus a query for car or automobile will retrieve essentially identical results; vehicle will be less accurate but will still retrieve many of the same images. So while word choice may be a significant consideration for a system like that of Jang et al., 1999, its impact on PictureQuest is minimal.

The use of WordNet as an aid to information retrieval is controversial, and some studies indicate it is more hindrance than help (e.g. Voorhees 1993, 1994, Smeaton, Kelledy and O'Donnell 1995). WordNet uses extremely fine-grained distinctions, which can interfere with precision even in monolingual information retrieval. In a cross-language application, the additional senses can add confounding mistranslations. If, on the other hand, WordNet expansion is constrained, the correct translation may be missed, lowering recall. In the PictureQuest application, we have tuned WordNet expansion levels and the corresponding weights attached to them so that WordNet serves to increase recall with minimal impact on precision (Flank 2000). This tuned expansion appears to be beneficial in the cross-language application as well.

Gilarranz, Gonzalo and Verdejo (1997) point out that, for cross-language information retrieval, some precision is lost in any case, and WordNet is more likely to enhance cross-linguistic than monolingual applications.

In fact, Smeaton and Quigley (1996) conclude that WordNet is indeed helpful in image retrieval, in particular because image captions are too short for statistical analysis to be useful. This insight is what led us to develop a proprietary image retrieval engine in the first place: fine-grained linguistic analysis is more useful that a statistical approach in a caption averaging some thirty words. (Our typical captions are longer than those reported in Smeaton and Quigley 1996).

\section{Translation Methodology}

We performed preliminary testing using two translation methodologies. For the initial tests, we chose European languages: French, Spanish, and German. Certainly this choice simplifies the translation problem, but in our case it also reflects the most pressing business need for translation. For the French, Spanish, and German tests, we used Systran as provided by AltaVista (Babelfish); we also tested several other Web translation programs. We used native speakers to craft queries and then translated those queries either manually or automatically and submitted them to PictureQuest. The resulting image set was evaluated for precision and, in a limited fashion, for recall.

The second translation methodology employed was direct dictionary translation, tested only for Spanish. We used the same queries for this test. Using an on-line Spanish-English dictionary, we selected, for each word, the top (top-frequency) translation. We then submitted this wordby-word translation to PictureQuest. (Unlike AltaVista, this method spellcorrected letters entered without the necessary diacritics.) Evaluation proceeded in the same manner. The word-by-word method introduces a weakness in phrase recognition: any phrase recognition capabilities in the retrieval system are defeated if phrases are not retained in the input. We can assume that the non-Englishspeaking user will, however, recognize phrases in her or his own language, and look 
them up as phrases where possible. Thus we can expect at least those multiword phrases that have a dictionary entry to be correctly understood. We still do lose the noun phrase recognition capabilities in the retrieval system, further confounded by the fact that in Spanish adjectives follow the nouns they modify. In the hombre de negocios example in the data below, both AltaVista and Langenscheidt correctly identify the phrase as multiword, and translate it as businessman rather than man of businesses.

The use of phrase recognition has been shown to be helpful, and, optimally, we would like to include it. Hull and Grefenstette 1996 showed the upper bound of the improvements possible by using lexicalized phrases. Every phrase that appeared was added to the dictionary, and that tactic did aid retrieval. Both statistical co-occurrence and syntactic phrases are also possible approaches. Unfortunately, the extra-system approach we take here relies heavily on the external machine translation to preserve phrases intact. If AltaVista (or, in the case of Langenscheidt, the user) recognizes a phrase and translates it as a unit, the translation is better and retrieval is likely to be better. If, however, the translation mistakenly misses a phrase, retrieval quality is likely to be worse. As for compositional noun phrases, if the translation preserves normal word order, then the PictureQuest-internal noun phrase recognition will take effect. That is, if jeune fille translates as young girl, then PictureQuest will understand that young is an adjective modifying girl. In the more difficult case, if the translation preserves the correct order in translating la selva africana, i.e. the African jungle, then noun phrase recognition will work. If, however, it comes out as the jungle African, then retrieval will be worse. In the architecture described here, fixing this problem requires access to the internals of the machine translation program.

\section{Evaluation}

Evaluating precision and recall on a large corpus is a difficult task. We used the evaluation methods detailed in Flank 1998. Precision was evaluated using a crossing measure, whereby any image ranked higher than a better match was penalized. Recall per se was measured only with respect to a defined subset of the images. Ranking incorporates some recall measures into the precision score, since images ranked too low are a recall problem, and images marked too high are a precision problem. If there are three good matches, and the third shows up as \#4, the bogus \#3 is a precision problem, and the too-low \#4 is a recall problem.

For evaluation of the overall cross-language retrieval performance, we simply measured the ratio between the cross-language and monolingual retrieval accuracy (C/M\%). This is standard; see, for example, Jang et al. 1999.

Table 1 illustrates the percentage of monolingual retrieval performance we achieved for the translation tests performed. In this instance, we take the precision performance of the human-translated queries and normalize it to $100 \%$, and adjust the other translation modalities relative to the human baseline.

\begin{tabular}{|l|l|l|}
\hline Language & $\begin{array}{l}\text { Raw } \\
\text { Precision (\%) }\end{array}$ & $\begin{array}{l}\text { C/M } \\
(\%)\end{array}$ \\
\hline French (Human) & 80 & 100 \\
\hline $\begin{array}{l}\text { French } \\
\text { (AltaVista) }\end{array}$ & 86 & 100 \\
\hline $\begin{array}{l}\text { French } \\
\text { (Transparent } \\
\text { Language) }\end{array}$ & 66 & 83 \\
\hline
\end{tabular}




\begin{tabular}{|l|l|l|}
\hline Language & $\begin{array}{l}\text { Raw } \\
\text { Precision (\%) }\end{array}$ & $\begin{array}{l}\text { C/M } \\
\text { (\%) }\end{array}$ \\
\hline French (Intertran) & 44 & 55 \\
\hline Spanish (Human) & 90 & 100 \\
\hline $\begin{array}{l}\text { Spanish } \\
\text { (AltaVista) }\end{array}$ & 53 & 59 \\
\hline $\begin{array}{l}\text { Spanish } \\
\text { (Langenscheidt } \\
\text { Bilingual } \\
\text { Dictionary) }\end{array}$ & 63 & 70 \\
\hline German (Human) & 80 & 100 \\
\hline $\begin{array}{l}\text { German } \\
\text { (AltaVista) }\end{array}$ & 54 & 68 \\
\hline
\end{tabular}

Several other factors make the PictureQuest application a particularly good application for machine translation technology. Unlike document translation, there is no need to match every word in the description; useful images may be retrieved even if a word or two is lost. There are no discourse issues at all: searches never use anaphora, and no one cares if the translated query sounds good or not.

In addition, the fact that the objects being retrieved were images greatly simplified the endeavor. Under normal circumstances, developing a user-friendly interface is a major challenge. Users with only limited (or nonexistent) reading knowledge of the language of the documents need a way to determine, first, which ones are useful, and second, what they say. In the PictureQuest application, however, the retrieved assets are images. Users can instantly assess which images meet their needs.

In conclusion, it appears that simple on-line translation of queries can support effective cross-language information retrieval, for certain applications. We showed how an image retrieval application eliminates some of the problems of cross-language retrieval, and how carefully tuned WordNet expansion simplifies word choice issues. We used a variety of machine translation systems, none of them high-end and all of them free, and nonetheless achieved commercially viable results.

\section{Appendix: Data}

\begin{tabular}{|c|c|c|}
\hline Source & Example & Score \\
\hline Prgsp & $\begin{array}{l}\text { 1. hombres reparando } \\
\text { carretera }\end{array}$ & \\
\hline Human & men repairing road & 100 \\
\hline AV & men repairing wagon & 0 \\
\hline Lang. & man repair road & 100 \\
\hline Orgsp & $\begin{array}{l}\text { 2. mujer vestida de rojo } \\
\text { comprando en ina ticha }\end{array}$ & 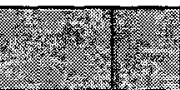 \\
\hline Human & $\begin{array}{l}\text { woman wearing red } \\
\text { shopping in store }\end{array}$ & 100 \\
\hline AV & $\begin{array}{l}\text { woman dressed red buying } \\
\text { in one tends }\end{array}$ & $\begin{array}{l}90(2 \text { of } \\
20 \mathrm{bad})\end{array}$ \\
\hline Lang. & $\begin{array}{l}\text { woman clothe red buy in } \\
\text { shop }\end{array}$ & $\begin{array}{l}\text { wearing } \\
\text { red is lost } \\
75 \text { ( } 5 \text { of } \\
20 \text { bad) }\end{array}$ \\
\hline Origsp & $\begin{array}{l}\text { 9. carios manejande porta } \\
\text { autopista. }\end{array}$ & 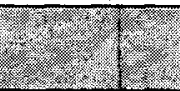 \\
\hline Human & $\begin{array}{l}\text { cars driving on the } \\
\text { highway }\end{array}$ & 100 \\
\hline $\mathrm{AV}$ & $\begin{array}{l}\text { cars handling by the } \\
\text { freeway }\end{array}$ & $\begin{array}{l}80(4 \text { of } \\
20 \mathrm{bad})\end{array}$ \\
\hline Lang. & $\begin{array}{l}\text { cart handle for the } \\
\text { expressway }\end{array}$ & 0 \\
\hline Ormop & $\begin{array}{l}4 \text { reones camando enta } \\
\text { selva atricana. }\end{array}$ & (2) \\
\hline Human & $\begin{array}{l}\text { lions hunting in the } \\
\text { African forest }\end{array}$ & $\begin{array}{l}80 \text { ( } 1 \text { of } 5 \\
\text { bad) }\end{array}$ \\
\hline $\mathrm{AV}$ & $\begin{array}{l}\text { lions hunting in the } \\
\text { African forest }\end{array}$ & $\begin{array}{l}80 \text { ( } 1 \text { of } 5 \\
\text { bad) }\end{array}$ \\
\hline Lang. & lion hunt in the jungle & $\begin{array}{l}45(11 \text { of } \\
20 \mathrm{bad})\end{array}$ \\
\hline Origsp & $\begin{array}{l}5 . \text { malabarista con usando } \\
\text { bolas de colores }\end{array}$ & \\
\hline Human & juggler using colorful balls & $\begin{array}{l}67 \text { ( } 1 \text { of } 3 \\
\text { bad) }\end{array}$ \\
\hline $\mathrm{AV}$ & $\begin{array}{l}\text { juggler with using balls of } \\
\text { colors }\end{array}$ & $\begin{array}{l}50(4 \text { of } 8 \\
\text { bad) }\end{array}$ \\
\hline Lang. & $\begin{array}{l}\text { juggler by means of use } \\
\text { ball colour }\end{array}$ & $\begin{array}{l}(0 ; \quad 1 \\
\text { should be } \\
\text { there) }\end{array}$ \\
\hline Origsp & $\begin{array}{l}\text { 6. ninos rubios jugando } \\
\text { con canicas }\end{array}$ & \\
\hline
\end{tabular}




\begin{tabular}{|c|c|c|}
\hline Source & Example & Score \\
\hline Human & $\begin{array}{l}\text { blonde children playing } \\
\text { with marbles }\end{array}$ & $\begin{array}{l}90 \text { (\#3 } \\
\text { should be } \\
\# 1 ; \\
\text { remainder } \\
\text { of top } 20 \\
\text { ok) }\end{array}$ \\
\hline AV & $\begin{array}{l}\text { blond children playing } \\
\text { with marbles }\end{array}$ & $\begin{array}{l}90(2 \text { of } \\
20 \mathrm{bad})\end{array}$ \\
\hline Lang. & $\begin{array}{l}\text { young fair play by means } \\
\text { of marble }\end{array}$ & $\begin{array}{l}50(1 \text { of } 2 \\
\text { bad) }\end{array}$ \\
\hline OrigSp & 7. poder adquisitivo & 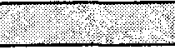 \\
\hline Human & buying power & \\
\hline $\mathrm{AV}$ & spending power & $\begin{array}{l}45(11 \text { of } \\
20 \mathrm{bad})\end{array}$ \\
\hline Lang. & purchasing power & 100 \\
\hline Origsp & $\begin{array}{l}\text { 8. exitoso hombre de } \\
\text { negocios en oficina? }\end{array}$ & \\
\hline$\overline{A V}$ & $\begin{array}{l}\text { successful businessman in } \\
\text { office }\end{array}$ & $\begin{array}{l}60(8 \text { of } \\
20 \mathrm{bad})\end{array}$ \\
\hline Lang. & $\begin{array}{l}\text { successful businessman in } \\
\text { office }\end{array}$ & $\begin{array}{l}6(8 \text { of } 20 \\
\mathrm{bad})\end{array}$ \\
\hline Origsp & $\begin{array}{l}\text { 9. madre e hija horneando } \\
\text { pan en la cocina. }\end{array}$ & \\
\hline Human & $\begin{array}{l}\text { mother and daughter } \\
\text { baking bread in the kitchen }\end{array}$ & $\begin{array}{l}100 \text { (but } \\
\text { no full } \\
\text { matches) }\end{array}$ \\
\hline$\overline{\mathrm{AV}}$ & $\begin{array}{l}\text { mother and daughter } \\
\text { [horneando-removed] } \\
\text { bread in the kitchen }\end{array}$ & $\begin{array}{l}30 \text { (14 of } \\
20 \mathrm{bad})\end{array}$ \\
\hline Lang. & $\begin{array}{l}\text { mother and child bake } \\
\text { bread in the kitchen }\end{array}$ & $\begin{array}{l}100 \quad \text { (but } \\
\text { no full } \\
\text { matches) }\end{array}$ \\
\hline Origsp & 10. vejez y soledad & 2 \\
\hline Human & old age and loneliness & 100 \\
\hline $\mathrm{AV}$ & oldness and solitude & 0 \\
\hline Lang. & old age and loneliness & 100 \\
\hline
\end{tabular}

\subsection{Spanish}

Human translations, tested on PictureQuest: $90 \%$ (normalize to $100 \%$ )

AltaVista: 53\% (59\% normalized)

Langenscheidt, word-by-word: 63\% (70\% normalized)

\subsubsection{AltaVista}

For AltaVista, we left out the words that AltaVista didn't translate.

\subsubsection{Langenscheidt}

Langenscheidt, word-by-word: $63 \%$ (70\% normalized)

For the Langenscheidt word-by-word, we used the bilingual dictionary to translate each word separately as if we knew no English at all, and always took the first translation. We made the following adjustments:

1. Left out "una," since Langenscheidt mapped it to "unir" rather than to either $a$ or one

\section{Translated "e" as and instead of $e$}

\subsection{French}

Human translations, tested on PictureQuest: $80 \%$

\section{AltaVista: 86\% (100\% normalized)}

Transparent Language (freetranslation.com): $66 \%$ (83\% normalized)

Intertran (www.intertran.net:2000): 44\% (55\% normalized)

[French examples originally drawn from http://humanities.uchicago.edu/ARTFL/proj ects/academie/1835.searchform.html:

French-French]

\begin{tabular}{|c|c|c|}
\hline Source & Example & Score \\
\hline OrigFr & 1. signes du zodiaque & \\
\hline Human & signs of the zodiac & 100 \\
\hline AV & signs of the zodiac & 100 \\
\hline TrLang & sign zodiaque & 0 \\
\hline IntrTran & [signes] any zodiac & 100 \\
\hline OngFr & 2. poisson dans Ileau & 2.2 \\
\hline Human & fish in water & $\begin{array}{l}30(14 \text { of } 20 \\
\text { bad) }\end{array}$ \\
\hline $\mathrm{AV}$ & fish : & $\begin{array}{l}30(14 \text { of } 20 \\
\text { bad) }\end{array}$ \\
\hline TrLang & fish i & $\begin{array}{l}30 \text { (14 of } 20 \\
\text { bad) }\end{array}$ \\
\hline IntrTran & fish at water & $\begin{array}{l}30(14 \text { of } 20 \\
\text { bad) }\end{array}$ \\
\hline Origkr & 3. Les maux d'oreille &  \\
\hline
\end{tabular}




\begin{tabular}{|c|c|c|}
\hline ource & Example & Score \\
\hline 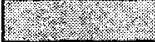 & douloureux & rige \\
\hline Human & inful earaches & 100 \\
\hline $\mathrm{AV}$ & aches & 100 \\
\hline TrLang & the painful ear evil & 0 \\
\hline IntrTran & $\begin{array}{l}\text { the [maux] [doreille]' } \\
\text { distressing }\end{array}$ & 0 \\
\hline Origfr & $\begin{array}{l}\text { 4. Prendre un lapin par } \\
\text { les oreilles }\end{array}$ & \\
\hline Human & $\begin{array}{l}\text { to take a rabbit by the } \\
\text { ears }\end{array}$ & $\begin{array}{l}65(7 \text { of } 20 \\
\text { bad) }\end{array}$ \\
\hline$\overline{\mathrm{AV}}$ & $\begin{array}{l}\text { To take a rabbit by the } \\
\text { ears }\end{array}$ & $\begin{array}{l}65(7 \text { of } 20 \\
\text { bad) }\end{array}$ \\
\hline TrLang & take a rabbit by the ears & $\begin{array}{l}65(7 \text { of } 20 \\
\text { bad) }\end{array}$ \\
\hline IntrTran & $\begin{array}{l}\text { capture a bunny by the } \\
\text { ears }\end{array}$ & $\begin{array}{l}80(1 \text { of } 5 \\
\text { bad) }\end{array}$ \\
\hline Origfr. & 5 Gohat qui vit dans tes: & \\
\hline Human & cat which lives in wood & $\begin{array}{l}45(11 \text { of } 20 \\
\text { bad) }\end{array}$ \\
\hline$\overline{\mathrm{AV}}$ & Cat & $\begin{array}{l}45(11 \text { of } 20 \\
\text { bad) }\end{array}$ \\
\hline \begin{tabular}{|l} 
TrLang \\
\end{tabular} & $\mathrm{d}$ & $\begin{array}{l}65(7 \text { of } 20 \\
\text { bad) }\end{array}$ \\
\hline Intr & $\begin{array}{l}\text { cat thanksgiving lives at } \\
\text { the forest }\end{array}$ & $\begin{array}{l}70(6 \text { of } 20 \\
\text { bad) }\end{array}$ \\
\hline OrigFr & 6. Sortir dune maison & 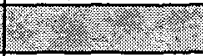 \\
\hline Human & to leave $\mathrm{a}$ & $\begin{array}{l}60(8 \text { of } 20 \\
\text { bad) }\end{array}$ \\
\hline$\overline{A V}$ & To & $\begin{array}{l}60(8 \text { of } 20 \\
\text { bad) }\end{array}$ \\
\hline TrLang & to & $\begin{array}{l}95 \text { (1 of } 20 \\
\text { bad) }\end{array}$ \\
\hline IntrTran & e' dwelling & $\begin{array}{l}90(18 \text { of } 20 \\
\text { bad) }\end{array}$ \\
\hline OrigFt & $\begin{array}{l}\text { 7. } 1 \text { r } \\
\text { char }\end{array}$ & \\
\hline Human & carpenter's tool & $\begin{array}{l}95(1 \text { of } 20 \\
\text { bad) }\end{array}$ \\
\hline $\bar{A}$ & ter & 100 \\
\hline TrLang & instrumen & 100 \\
\hline IntrTran & implement any carpenter & $\begin{array}{l}35(13 \text { of } 20 \\
\text { bad) }\end{array}$ \\
\hline OrigFr & 8. & \\
\hline Human & to $\mathrm{p}$ & 100 \\
\hline $\mathrm{AV}$ & to play o & 100 \\
\hline TrLang & to play the violin & 100 \\
\hline IntrTran & gamble any violin & 0 \\
\hline & 9. Les p & \\
\hline Hun & pleasures of the & 100 \\
\hline
\end{tabular}

\begin{tabular}{|l|l|l|}
\hline Source & Example & Score \\
\hline AV & Pleasures of the body & 100 \\
\hline TrLang & the pleasures of the body & 100 \\
\hline IntrTran & the delight any body & 0 \\
\hline Origr & $\begin{array}{l}\text { 10. une jeune fille mange } \\
\text { du fruit }\end{array}$ & \\
\hline Human & a girl eats fruit & 100 \\
\hline AV & a girl eats fruit & 100 \\
\hline TrLang & a girl eats fruit & 100 \\
\hline IntrTran & a girl am eating any fruit & $\begin{array}{l}65(7 \text { of } 20 \\
\text { bad) }\end{array}$ \\
\hline
\end{tabular}

\subsection{German}

Human translations, tested on PictureQuest: $80 \%$ ( $100 \%$ normalized)

\section{AltaVista 54\% (68\% normalized)}

\begin{tabular}{|c|c|c|}
\hline Source & Example & Score \\
\hline Origar & 1. Golfplatz: & \\
\hline Human & boys golf course & 95 \\
\hline$\overline{\mathrm{AV}}$ & golf course & 95 \\
\hline OrigGr & 2. kunstliche Paradiese & 6.1.2. \\
\hline Human & artificial paradise & 100 \\
\hline AV & artificial paradiese & 0 \\
\hline OrigGr & 3. Solarenergie fur Autos & $4=2$ \\
\hline Human & solar energy for automobiles & 95 \\
\hline$\overline{A V}$ & solar energy for auto & 95 \\
\hline OrigGr & $\begin{array}{l}\text { 4. wanderungen durch den } \\
\text { wald }\end{array}$ & \\
\hline Human & hiking through the forest & 90 \\
\hline AV & migrations by the forest & 0 \\
\hline OrigGr & 5. Elefanten im $\mathrm{ZoO}$ & 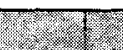 \\
\hline Human & an elephant in a zoo & $\begin{array}{l}25 \\
(\# 17 \\
\text { should } \\
\text { be \#2) }\end{array}$ \\
\hline AV & elephant in the zoo & 100 \\
\hline OrigGr & $\begin{array}{l}\text { 6. die Synthese der } \\
\text { Desoxynribonukleinsăure }\end{array}$ &  \\
\hline Human & $\begin{array}{l}\text { the synthesis of } \\
\text { desoxyribonucleic acid }\end{array}$ & 100 \\
\hline $\mathrm{AV}$ & $\begin{array}{l}\text { the synthesis of the } \\
\text { Desoxynribonukleinsaeure }\end{array}$ & $\mathbf{0}$ \\
\hline OrigGr & 7. schwarze Autos & \\
\hline Human & black cars & 100 \\
\hline$\overline{\mathrm{AV}}$ & black auto & 100 \\
\hline OrigGr & 8. jungen zusammen spielen & 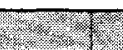 \\
\hline Human & playing together & 60 \\
\hline AV & young together play & 35 \\
\hline
\end{tabular}




\begin{tabular}{|l|l|l|}
\hline Source & Example & Score \\
\hline OrigGr & 9. Damen im blau & \\
\hline Human & women in blue & 65 \\
\hline AV & Ladies in blue & 75 \\
\hline OrigGr & 10. Damen auf Arbeit & \\
\hline Human & woman at work & 65 \\
\hline AV & Ladies on work & 40 \\
\hline
\end{tabular}

\section{Acknowledgements}

I am grateful to Doug Oard for comments on an earlier version of this paper.

\section{References}

Ballesteros, Lisa, and W. Bruce Croft, 1997. "Phrasal Translation and Query Expansion Techniques for Cross-Language Information Retrieval," in $A A A I$ Spring Symposium on Cross-Language Text and Speech Retrieval, Stanford University, Palo Alto, California, March 24-26, 1997.

Fellbaum, Christiane, ed., 1998. WordNet: An Electronic Lexical Database. Cambridge, MA: MIT Press.

Flank, Sharon. 2000. "Does WordNet Improve Multimedia Information Retrieval?" Working paper.

Flank, Sharon. 1998. "A Layered Approach to NLPBased Information Retrieval," in Proceedings of COLING-ACL, 36th Annual Meeting of the Association for Computational Linguistics, Montreal, Canada, 10-14 August 1998.

Gilarranz, Julio, Julio Gonzalo and Felisa Verdejo. 1997. "An Approach to Conceptual Text Retrieval Using the EuroWordNet Multilingual Semantic Database," in AAAI Spring Symposium on CrossLanguage Text and Speech Retrieval, Stanford University, , Palo Alto, California, March 24-26, 1997. (http://www.clis.umd.edu/dlrg/filter/sss/papers)

Grefenstette, Gregory, ed., 1998. Cross-Language Information Retrieval. Norwell, MA: Kluwer.

Hull, David A. and Gregory Grefenstette, 1996. "Experiments in Multilingual Information Retrieval," in Proceedings of the $19^{\text {th }}$ International Conference on Research and Development in Information Retrieval (SIGIR96) Zurich, Switzerland.

Jang, Myung-Gil, Sung Hyon Myaeng, and Se Young Park, 1999. "Using Mutual Information to
Resolve Query Translation Ambiguities and Query Term Weighting," in Proceedings of $37^{\text {th }}$ Annual Meeting of the Association for Computational Linguistics, College Park, Maryland.

McCarley, J. Scott, 1999. "Should We Translate the Documents or the Queries in Cross-Language Information Retrieval?"

Resnik, Philip and Yarowsky, David, in press. "Distinguishing Systems and Distinguishing Sense: New Evaluation Methods for Word Sense Disambiguation," Natural Language Engineering.

Smeaton, Alan F., F. Kelledy and R. O'Donnell, 1995. "TREC-4 Experiments at Dublin City University: Thresholding Posting Lists, Query Expansion with WordNet and POS Tagging of Spanish," in Donna K. Harman (ed.) NIST Special Publication 500-236: The Fourth Text REtrieval Conference (TREC-4), Gaithersburg, MD, USA: Department of Commerce, National Institute of Standards and Technology. (http://trec.nist.gov/pubs/trec4/t4_proceedings.html)

Smeaton, Alan F. and I. Quigley, 1996. "Experiments on Using Semantic Distances Between Words in Image Caption Retrieval," in Proceedings of the 19th International Conference on Research and Development in Information Retrieval (SIGIR96) Zurich, Switzerland.

Voorhees, Ellen M. 1994. "Query Expansion Using Lexical-Semantic Relations," in Proceedings of the $17^{\text {th }}$ International ACM SIGIR Conference on Research and Development in Information Retrieval, pp. 61-70.

Voorhees, Ellen M. 1993. "Using WordNet to Disambiguate Word Senses for Text Retrieval," in Proceedings of the $16^{\text {th }}$ International ACM SIGIR Conference on Research and Development in Information Retrieval, pp. 171-180.

Voorhees, Ellen M. and Donna K. Harman, editors, 1999. The $7^{\text {th }}$ Text Retrieval Conference (TREC-7). 